ConNotas. Revista de crítica y teoría literarias / Vol. III, NÚms. 4-5/ 2005

\title{
Notas
}

\section{Algunas notas sobre el formalismo ruso}

\author{
SAMUEL GoRDON*
}

Resumen:

Este ensayo tiene como objetivo hacer un estudio histórico sobre el surgimiento de los formalistas rusos y sus contribuciones hacia la crítica literaria posterior. Mencionan a los principales teóricos que inician este movimiento, a partir de dos pequeños grupos de estudiosos: la OPOIAZ (Sociedad para el Estudio del Lenguaje Poético), con sede en San Petersburgo, y el Círculo Lingüístico de Moscú, cuyos integrantes eran fundamentalmente lingüistas. Se analiza también el Círculo Lingüístico de Praga, inspirado inicialmente en los estudios de los formalistas rusos. D urante algunos años este último constituyó una fuerza de vanguardia para el desarrollo de los estudios lingüísticos y literarios en Europa. En este estudio se analizan algunas innovaciones de los formalistas, como el conferirle a la crítica literaria un carácter distinto al que tenía en etapas precedentes; con un objeto de estudio claramente especificado y un método propio que en aquel momento disiparía muchas de las dudas aún presentes en los diversos campos del saber.

Palabras clave:

Formalistas rusos, Víctor Shkovsky, Roman Jakobson, O PO IAZ, Círculo Lingüístico de Moscú, crítica lateraria del siglo XX, historia del formalismo ruso.

* Universidad Iberoamericana. 
La expansión de las nuevas direcciones y tendencias del pensamiento científico y metodológico llegó a influir inexorablemente en la labor crítica de la filología y los estudios literarios de principios del siglo XX. En un lúcido ensayo, Jakobson (7 y ss.) estableció tempranamente los imprescindibles deslindes - a partir de la lingüística- entre la genética de una obra y sus derivaciones en la literatura. Su planteo inicial enmarca de manera significativa la pobre situación que guardaban los estudios lingüísticos y literarios en la Europa finisecular.

Con todo [escribe Jakobson] el realismo ingenuo siguió expandiéndose, y aun se fortificó todavía a principios de nuestro siglo en un terreno, el de las disciplinas humanísticas, cuyos representantes tienen tanto quehacer acopiando materiales y realizando otras tareas concretas, que no se inclinan a la revisión de los supuestos filosóficos, con lo cual, naturalmente, quedan atrasados en lo que toca a principios teóricos.

Y asevera más adelante que, por ajena que pueda resultar esa visión a los investigadores modernos, en múltiples terrenos de la ciencia de la cultura sobrevivía ese lastre heredado que entorpecía el desarrollo de los estudios literarios.

A principios del siglo pasado, la situación y el nivel de estos estudios en Rusia se parecían a los de otros países europeos. De una parte, la historia literaria académica, enraizada en el positivismo y dominada por la erudición, prestaba muy poca atención a los valores estéticos; de otra, existía una crítica literaria impresionista, poco rigurosa y aun menos seria, que tenía sus tribunas particularmente en periódicos y revistas. Las nuevas generaciones de las universidades rusas en vísperas de la Primera Guerra Mundial, insatisfechas con los procedimientos y resultados de la historia literaria académica y con la ligereza diletante de quienes ejercían la crítica impresionista, comenzaron a buscar nuevas opciones. Aun cuando existen divergencias respecto a la fecha exacta del origen del movimiento formalista ruso, sus más tempranos antecedentes suelen 
ubicarse hacia 1914, al aparecer un ensayo de Víctor Shklovsky sobre la poesía futurista titulado L a resurrección de la palabra. La teoría - denominada desde fuera y despectivamente como formalista-, comenzó a desarrollarse a partir de los encuentros, discusiones y publicaciones de dos pequeños grupos de estudiantes y estudiosos: la 0 POIA Z (Sociedad para el Estudio del Lenguaje Poético) y el Círculo Lingǘstico de Moscú. El primer grupo, con sede en San Petersburgo, estaba integrado por estudiantes de literatura unidos especialmente por dos intereses comunes: su insatisfacción con la forma en que se estudiaba la literatura y un interés real y positivo por el movimiento poético del futurismo ruso. Liderado por Víctor Shklovsky, incluía entre sus integrantes a Boris Eichenbaum, Osip Brik y Yuri Tinianov (Jefferson 16). Por su parte, los integrantes del grupo de Moscú eran fundamentalmente lingüistas interesados en extender su disciplina al estudio del lenguaje poético en su propio ámbito. Su más conocido y destacado exponente es el teórico Roman Jakobson y entre otros se encontraban Fedor Buslaev y G. O. Vinokur (Aguiar 397).

Aunque existieron marcadas diferencias en cuanto a énfasis e interés en las aportaciones individuales de los formalistas, el verdadero valor teórico de su labor puede y debe entenderse como un esfuerzo colectivo para establecer una base teórica coherente de los estudios literarios.Tanto el OPOIA Z como el Círculo Lingüístico de Moscú estaban estrechamente vinculados con los movimientos artísticos de vanguardia, particularmente el futurismo, y no era infrecuente la participación de Mayakovsky en las reuniones de dichos grupos. Después de la revolución de 1917, los formalistas rusos continuaron con sus actividades. Año tras año aumentaban sus publicaciones a medida que sus estudios cobraban gran influencia entre los sectores universitarios. Fue entre 1924 y 1925 cuando comenzó a ganar fuerza la oposición de los intelectuales y dirigentes marxistas a las doctrinas del formalismo. Iniciándose entonces un periodo de intensas polémicas y violentos ataques. Ya en 1923, León Trotsky había dedicado un capítulo de su obra Literatura y revolución a criticar a los formalistas, sus bases teóricas y métodos. 
Condenó especialmente su concepción neokantiana de los valores ideológicos como entidades autónomas, desarraigadas del proceso histórico. ${ }^{1}$

A las objeciones de Trotsky habrían de seguir las de Bujarin y Lunatcharsky. Las doctrinas formalistas, consideradas cada vez más heréticas frente a la pura ortodoxia marxista-leninista, se fueron replegando ante la enorme presión política que se ejerció en contra del grupo, hasta que sus defensores quedaron reducidos al silencio. El final del formalismo ruso suele marcarse hacia enero de 1930, cuando se realiza una recapitulación - debida también a Víctor Shklovsky- que trataba de resumir los alcances del movimiento. Si bien a fines de ese año el formalismo se extinguía, dejaba su simiente para los trabajos que habría de desarrollar el Círculo Lingǘstico de Praga.

Roman Jakobson, quien había abandonado Moscú para dirigirse a Checoslovaquia en 1920, contribuyó a fundar el Círculo Lingüístico de Praga, el cual se reunió por primera vez el 6 de octubre de 1926 en la capital checa. Congregaba a lingüistas y críticos literarios -además de Jakobson- como Jan Mukarovsky y Nikolai S. Trubetskoy, cuyos Principios de fonología - publicado en 1949- habrían de servir de modelo para la A ntropología altural de Claude Lévi-Strauss. ${ }^{2} \mathrm{Al}$ igual que sus colegas moscovitas, los checos eran

${ }^{1}$ Es revelador detenerse en las objeciones de Trostky contra el trabajo de Shklovsky, Jakobson y Tomachevsky; en particular argumenta que la poesía y su estudio no consisten en esos recuentos de vocales, consonantes, sílabas y adjetivos a los que se entregan los formalistas. Sin embargo, concede que: "La escuela formalista es la primera escuela de arte científica", gracias a la cual "la teoría del artey, en parte el arte mismo, se han elevado al fin del estudio de la alquimia al de la química". León Trotsky, "La escuela formalista de poesía y el marxismo", Literatura y revolución (París: Ediciones de Ruedo Ibérico, 1968).

${ }^{2}$ A cerca de algunos trabajos teóricos y sus alcances, véase $\mathrm{E} l$ Círculo de Praga, volumen colectivo que reúne textos de Trnka, Vachek, Trubetskoy, Mathesius y Jakobson; reunidos, traducidos y prologados por Joan A. Argente (Barcelona: Anagrama, 1972). 
sobre todo lingüistas y, por tanto, no alteraron de manera significativa las bases de la teoría literaria de los formalistas rusos. Evaluado en su conjunto, el Círculo Lingüístico de Praga reafirmó ciertos postulados del formalismo ruso tardío (Jefferson 17). D urante algunos años, el Círculo Lingüístico de Praga constituyó una fuerza de vanguardia para desarrollar los estudios lingǘsticos y literarios en Europa. En particular, produjo valiosas publicaciones no sólo sobre el estructuralismo sino también acerca de las relaciones entre poética y semiótica (Aguiar 399).

Más importante aún que la pervivencia -a través de este conducto- de las doctrinas formalistas, ha sido el papel primordial que sus ideas han desempeñado en el desarrollo del estructuralismo parisino de la década de los sesenta y, muy particularmente, en los trabajos de Tzvetan Todorov y Gérard G enette.

Fernando Lázaro Carreter establece que los formalistas rusos intentaron proseguir la empresa ateniense, interrumpida durante muchos siglos (10). D urante este vasto periodo, los críticos literarios se apartaron cada vez más del ómo de los textos y dejaron de inquirir acerca de las técnicas, los recursos y los materiales verbales con que el artista teje su obra (10). El esfuerzo de los formalistas permitió que los estudios literarios se desviaran menos de su objeto de estudio - el libro o el poema construido con palabras-, ya que sólo por estar dispuestas así y no de otro modo, esas palabras desencadenan en el lector el placer de leer (11). Al formalismo ruso se debe, entonces, el primer intento de conferir a la crítica literaria un carácter bien definido, con un objeto de estudio claramente especificado y un método propio, que permitiera eliminar la confusión reinante entre los diversos campos del saber. Se esforzó para justificar la independencia de los estudios literarios como una disciplina específica y autónoma. Así, los estudiosos de la literatura dejarían de ser etnógrafos, historiadores o filósofos de segundo grado (Jefferson 18).

A partir del Círculo de Praga -y en particular con los trabajos de René Wellek y Roman Jakobson- se deslindaron los campos de estudio para lograr un enfoque formal del texto literario. Lo que antes 
del formalismo había sido una mescolanza indiscriminada de crítica impresionista, datos históricos, biográficos, anecdóticos, psicológicos, sociológicos y genéticos de una obra, etc., quedaría dividido en tres áreas claramente delimitadas (Aguiar 400 y ss). A ) El acceso ex trínseco al estudio de la literatura, que incluya junto con lo literario, lo biográfico, lo psicológico, lo social, las ideas y las relaciones de la literatura con las demás artes. B) El estudio intrínseoo de la literatura, que permita el acceso al modo de ser de una obra de arte literaria, atendiendo a la eufonía, ritmo, métrica, estilística, estilo, imágenes, metáforas, símbolos, naturaleza y formas de la ficción narrativa, estudio de los géneros literarios, en suma, la valoración de todos los elementos intrínsecos del texto. Y C), La historia literaria: la difusión de las doctrinas formalistas, originalmente escritas en lenguas eslavas, y, más que nada, la posibilidad de su estudio y visión de conjunto, se vio largamente postergada por la falta de traducciones. No fue sino hasta 1955 en que apareció la obra de Víctor Erlich, que habría de comenzar el rescate de las ideas rectoras del formalismo.

La primera colección de textos de formalistas rusos traducida a una lengua de mayor difusión fue el volumen titulado Théorie de la Littérature. Textes des Formalistes ruses réunis, presentés et traduits. Esta antología incluye artículos o capítulos de obras de mayor aliento debidos a Eichenbaum, Shklovsky, Jakobson, Vinogradov, Tinianov, Brik, Tomachevsky y Propp. La primera parte se centra en los estudios literarios y está ordenada cronológicamente; la segunda, se ocupa de la literatura en sí misma y sigue un orden sistemático. Refiriéndose de manera indirecta a un concepto original de Shklovsky -que examinaremos más adelante en detalle-, Todorov cita al matemático padre de la cibernética: "Como buen formalista, Norbert Wiener afirma: 'Aun en los grandes clásicos del arte y de la literatura no se encuentra ya gran cosa de su valor informativo porque el público se ha familiarizado con su contenido' " (Todorov 12, las cursivas son mías). Señala luego que 
Otro principio adoptado desde el comienzo por los formalistas es el de colocar la obra en el centro de sus preocupaciones; rehuyen el enfoque psicológico, filosófico o sociológico que regía entonces la crítica rusa. En ese punto, sobre todo, los formalistas se distinguen de sus predecesores: según ellos no se puede explicar la obra a partir de la biografía del escritor, ni a partir de un análisis de la vida social contemporánea. (12)

Según Todorov, antologar los quince años de intensa actividad de los formalistas - quienes produjeron una obra considerable- supone una elección forzosa que, aun siendo inevitablemente subjetiva, busca no deformar la imagen de la doctrina. Trataremos de puntualizar ciertos aspectos abordados específicamente por algunos integrantes del movimiento formalista, que, aun cuando no proporcionen una visión de conjunto del amplio espectro de intereses e inquietudes que ocupó a muchos de sus miembros, ${ }^{3}$ pueden servir de atisbo a la profundidad y los alcances de sus hallazgos y soluciones. Jameson precisa que "los primeros pasos de los formalistas tenían [sic] que ser negativos y su objetivo era separar el sistema literario de otros sistemas extrínsecos" (53) y clasifica además las polémicas existentes, en tres categorías generales: 1) Las que consideraban la literatura como portadora de un mensaje o contenido filosófico. 2) Las que intentaban un análisis genético de la literatura con un enfoque biográfico o mediante un estudio de sus fuentes. Y 3), las que tendían a convertir la obra literaria en una técnica o en un impulso psicológico particulares. A partir de esta última comienza

${ }^{3}$ Recordemos-escribe Todorov- los principales temas teóricos: la relación entre lengua emocional y lengua poética (R. Jakobson); la constitución fónica del verso (R. Jakobson); la entonación como principio constructivo del verso (B. Eichenbaum); el metro, la norma métrica, el ritmo en verso y en prosa (B. Tomachevsky); la relación entre ritmo y semántica en poesía (Y. Tinianov); la metodología de los estudios literarios (Y. Tinianov); la estructura del cuento fantástico (V. Propp); la tipología de las formas narrativas (V. Schklovsky); etc. Estos textos aparecieron -en su mayor parte- en revistas artísticas y fueron materia de amplia discusión. 
precisamente a oponerse el artículo de Shklovsky a la posición de Potebniá, para quien la poesía era "pensamiento en imágenes". Para los formalistas -y para Shklovsky en particular- el objeto de los estudios literarios es analizar las diferencias implícitas en la oposición entre el lenguaje poético y práctico, apoyándose en el concepto de extrañamiento (que veremos más adelante en detalle) para focalizar con claridad esas diferencias (Jefferson 20). Es la "literariedad" y no ésta 0 aquella obra, de éste 0 aquél autor, el objeto de los estudios literarios. En su etapa más temprana, la cuasi-sinonimia entre literariedad y forma fue el concepto que, acaso, mejor caracterizó al formalismo (Jefferson 21). Ya en 1914 el antecitado folleto de Shklovsky L a resurreoción de la palabra, refiriéndose parcialmente a Potebniá y a Veselovsky, postulaba como rasgo distintivo de la percepción estética el principio de la sensación de la forma (Eichenbaum 30).

\section{"El arte como artificio"}

En este artículo Shklovsky es contestatario contra la obra $\mathrm{N}$ otas sobre la teoría de la literatura de Potebniá, editada en 1905 por su discípulo O svianiko Kulikovsky. En ella se recogen algunas ideas de Potebniá sobre la función de las imágenes a partir del fenómeno artístico. Según palabras de éste: "La relación de la imagen con lo que ella explica puede ser definida de la siguiente manera: a) la imagen es un predicado constante para sujetos variables, un punto constante de referencia para percepciones cambiantes; b) la imagen es mucho más simple y mucho más clara de lo que explica" (Shklovsky 55). Rápidamente -y de una manera asaz elegante, considerando el aspecto polémico- Shklovsky desmonta los argumentos de que "sin imágenes no hay arte", y demuestra cómo se puede pasar a un arte desprovisto de imágenes, para luego afirmar: "El pensamiento por imágenes no es en todo caso el vínculo que une todas las disciplinas del arte, ni siquiera del arte literario; el cambio de imágenes no constituye la esencia del desarrollo poético" (56). 
Luego se detiene a analizar un procedimiento poético que André Bieli admiraba en los poetas rusos del siglo XVIII, que consistía en colocar los adjetivos después de los sustantivos, hecho al cual Bieli atribuía un valor artístico y un carácter intencional. El objeto, entonces, puede ser - afirmaba Shklovsky-: 1) creado como prosaico y percibido como poético; y 2) creado como poético y percibido como prosaico. De ahí concluye que, para Potebniá, poesía sería igual a imagen, y ésta, a su vez, sería igual a símbolo (aludiendo muy concretamente a los simbolistas). Aquí se hallaría una de las razones que llevaron a Potebniá a esa tesitura, ya que no distinguía la lengua de la poesía de la lengua de la prosa; lo cual, a su vez, le impedía percibir que existen dos tipos de imágenes: la imagen como medio práctico de pensar, de agrupar los objetos en clases; y la imagen poética, como medio de refuerzo de la impresión. En este punto Shklovsky pone de relieve que la imagen, lejos de constituir el factor esencial del lenguaje poético, es sólo uno de los muchos elementos del sistema de procedimientos artísticos utilizado por el escritor, siendo su función igual a la de la simetría, la hipérbole, la reiteración, etc. Los conceptos de imaginística y de lenguaje poético distan mucho de ser coextensivos porque, de una parte, las imágenes surgen no sólo en el lenguaje poético sino también en diferentes niveles lingüísticos y, por otra, puede existir un lenguaje poético sin imágenes (Aguiar 401). Shklovsky establece luego la diferencia entre metonimia y metáfora - aunque no la considera muy importante- para expresar posteriormente una afirmación cardinal: "la imagen poética es uno de los recursos de la lengua poética; la imagen prosaica es un medio de la abstracción" (58).

La segunda parte de su artículo se basa en una cita de Spencer sobre la economía de la atención, tomada de su libro Filosofía del estilo, y terminará finalmente refutándolo al establecer dos tipos de ritmo:1) el ritmo prosaico, que constituye un factor automatizante; y 2), el ritmo estético (o poético), que consiste en un ritmo prosaico transgredido. Shklovsky está en contra de aplicar la ley de la economía de las fuerzas creadoras - enunciada por Herbert Spencer- al lenguaje poético, porque considera que dicha ley es verdadera en el 
lenguaje cotidiano, pero que no es válida para aquél. La oposición esencial entre las leyes del lenguaje cotidiano y el lenguaje poético es la que se da entre la automatización y la perceptibilidad (A guiar 401). Para comprobarlo, analiza exhaustivamente algunos pasajes de Tolstoy, G ogol, Hamsum y otros, centrándose en el procedimiento que consiste en no llamar al objeto por su nombre, sino en describirlo como si se viera por primera vez y en tratar cada acontecimiento como si fuera nuevo; además, en la descripción del objeto no emplea los nombres que generalmente se dan a sus partes, sino otras palabras tomadas de la descripción de las partes correspondientes a otros objetos (Shklovsky 61).

La actividad del hombre tiende invariablemente a la rutina, el hábito y el automatismo. Así acontece con el lenguaje cotidiano: la frase queda muchas veces inacabada, la palabra se profiere sólo en parte, tienen libre curso los estereotipos verbales, etc.; por eso, en la comunicación proporcionada por el lenguaje cotidiano, los objetos se perciben de manera esfumada, sólo por uno de sus elementos o por sus caracteres genéricos y superficiales. El lenguaje poético, por el contrario, presenta el mundo en todo su frescor: el escritor deforma la realidad para atraer mejor la atención del lector y su recurso básico para presentarla es mediante la singularización de los objetos (Aguiar 401). Habiendo establecido que "la finalidad del arte es dar una sensación del objeto como visión y no como reconocimiento; los procedimientos del arte son: el de la singularización de los objetos, y el que consiste en oscurecer la forma, en aumentar la dificultad y la duración de la percepción", llega luego Shklovsky a formular su afirmación más importante: "El acto de percepción es en arte un fin en sí y debe ser prolongado. El arte es un medio de ex perimentar el devenir del objeto: lo que ya está 'realizado' no interesa para el arte" (Shklovsky 60, las cursivas son mías).

Este procedimiento de ex trañamiento (en ruso ostranenie) ${ }^{4}$ es el concepto operativo más importante que se puede extraer de todo el 
artículo. Shklovsky define una amplia cantidad de términos, pero éste - que desfamiliariza, que singulariza, que ex traña las cosas que han devenido habituales o automáticas-, es el más importante. Al respecto, Eichenbaum, en su Teoría del "M étodo Formal", escribe que el trabajo de Shklovsky representa una suerte de manifiesto del método formal, que abrió el camino del análisis concreto de la forma. Aquí se ve claramente el distanciamiento que se abre entre los formalistas y Potebniá y, por lo tanto, entre sus principios y los del simbolismo (Eichenbaum 31). Hay que recordar que Shklovsky publicó su artículo en 1917 y, de hecho, la coherente teoría literaria que manejó con posterioridad el movimiento formalista hubiera sido imposible sin su contribución inicial (Jameson 57). Aun cuando los verdaderos alcances de sus puntualizaciones comenzaron a vislumbrarse mucho más tarde (Jefferson 22), ya entonces la famosa definición del arte como un extrañamiento - ostranenie- de los objetos, como una renovación de la percepción, revestiría la forma de una ley psicológica (Jameson 59).

Algo que la crítica opositora del formalismo no comprendió correctamente fue el hecho de que, debido a la posibilidad de que los recursos y artificios literarios perdieran su capacidad de extrañamiento, los formalistas establecieron la distinción entre recurso y función. El efecto de extrañamiento de un recurso no depende de su existencia como tal, sino de la función que cumple en la obra en que se emplea, ya que el mismo recurso puede ser utilizado en una amplia variedad de funciones potenciales (Jefferson 22). 0, como lo expresara Jakobson muchos años más tarde, "Ni Tinianov, ni Shklovsky, ni Mukarovsky, ni yo hemos declarado que el arte es una esfera cerrada. Lo que enfatizamos no es el separatismo del arte, sino la autonomía de la función estética". Es esta autonomía, la del

emplea A guilar e Silva para referirse al procedimiento en cuestión-, es traducido al inglés por Ann Jefferson (19) como desfamiliarización; sugerimos atenernos mejor en español al término "extrañamiento" (según lo explica Jefferson: making strange), como lo utiliza Jameson en su estudio ya citado. 
predominio de la función estética por sobre los otros elementos componentes de una obra, lo que justifica la existencia de una ciencia literaria (Jefferson 23).

O sip Brik resumió algunas ideas del OPOIAZ, diciendo que no hay poetas o figuras literarias sino poesía y literatura (en lo que se refiere al tema de estudio de la ciencia literaria). Algo de esto asumió $\mathrm{V}$. Vinogradov al referirse a la estilística y sus objetos de estudio; en un libro escrito en 1922, ${ }^{5}$ afirmaba que lo importante era abordar "la tarea de conocer el estilo individual del escritor -independientemente de toda tradición, de toda otra obra contemporánea y, en su totalidad, como sistema lingüístico- y su organización estética, ello debe preceder a toda investigación histórica".

Aunque Vinogradov nunca se adhirió al grupo formalista, en muchas de sus proposiciones tempranas, sus preocupaciones de orden lingǘstico y estilístico reflejan una influencia incontestable de los formalistas. Con una concisión y claridad poco comunes, Vinogradov trata la relación entre el estudio sincrónico y el estudio diacrónico en el análisis estilístico de un texto ruso del siglo XVI. Haciendo gala de sus conocimientos lingüísticos -conocía perfectamente los trabajos de Baudoin de Courtenay, Saussure, Sechehaye y otros- demuestra la naturaleza insatisfactoria de la metodología aplicada a ciertos estudios efectuados entonces en Rusia, debido a la confusión de dos puntos de vista: el del estudio funcional inmanente y el del estudio histórioo. Así, Vinogradov -al igual que Propp- acepta la concepción de Shklovsky en cuanto al manejo de los recursos. Vladimir Propp tampoco encuentra muchas dificultades para demostrar que un cuento determinado puede ser el mismo, independientemente de que la figura en cuestión sea un lobo, un dragón, un ogro 0, incluso, un objeto de otro tipo. Además Propp - como

${ }^{5}$ Nos referimos aquí a un breve artículo, "Sobre la tarea de la estilística", que es el extracto del libro con el mismo nombre que apareciera en 1923. El artículo se halla compilado por T. Todorov en la colección de textos sobre el formalismo ruso a la que nos hemos estado refiriendo (81-85). 
Vinogradov- establece la diferencia entre horizontal y vertical, parecida por un lado a las categorías saussureanas de lo sintagmático y lo asociativo y por otro a la distinción de Shklovsky entre el recurso básico (ex trañamiento efectivo) y la motivación (Jameson 72). De ahí que desde el punto de vista formal el concepto de ostranenie presenta tres ventajas claras: 1) distingue la literatura, o sea el sistema puramente literario, de cualesquiera otros modos verbales existentes; 2) permite establecer una jerarquía interna dentro de la propia obra literaria, y 3), crea una nueva concepción de la historia literaria, no como la continuidad tradicional, sino, concebida como una serie de discontinuidades abruptas, de rupturas con el pasado, donde cada nuevo presente literario se ve como un rompimiento con los cánones artísticos dominantes de la generación inmediatamente anterior (Jameson 60-61). A partir de la noción básica de ostranenie comenzó a surgir toda una teoría literaria: primero por medio del aislamiento del sistema puramente literario; después, mediante un modelo de las diferentes relaciones que se dan en ese sistema sincrónico; y, por último, con un regreso a la diacronía al analizar el tipo de cambio de un estado sincrónico a otro (Jameson 62).

También el concepto de intertex tualidad estaba ya implícito en el formalismo ruso y en un punto muy cercano a la médula de la discusión con los marxistas. La tradicional prioridad de la realidad por sobre la literatura fue revertida por el formalismo, a partir de su principio - casi axiomático- de que la literatura deriva de otros textos literarios y no de fuentes extraliterarias y de que la realidad deviene irrelevante para la creación y la crítica literarias. Desde el punto de vista de los formalistas, todo cambio en la forma literaria no está determinado por los cambios que acontecen en la realidad, sino por la necesidad de revitalizar formas ya automatizadas de la literatura (Jefferson 26). Hay que recordar, sin embargo - en la prosecución de esta controversia con la crítica marxista- que la escuela de Mijaíl Bajtín se basa en la premisa de que todo uso de la lengua, incluso el literario, es simultáneamente social e ideológico.

A pesar de su enfoque innovador de la historia literaria como series discontinuas, los formalistas no llegaron a explicar cómo la 
historia literaria se insertaba en otras series históricas. Considerando la dispersión política de que fueron objeto, es muy difícil saber si esto se debía a limitaciones en cuanto a sus alcances teóricos o si quedó trunco el trabajo que les hubiera conducido a desarrollos más profundos y soluciones más amplias. Cualquiera que sea el valor último de su pensamiento sistemático, la crítica literaria tiene por fuerza que partir de donde ellos lo hicieron (Jameson 52).

\section{Bibliografía}

Aguiar e Silva, Víctor Manuel de. Teoría de la literatura. Madrid: Gredos, 1972.

Argente, Joan A., comp. E 1 Círculo de Praga. Barcelona: Anagrama, 1972.

Eichenbaum, Boris. "La teoría del 'método formal'" (Todorov). Erlich, Víctor. R ussian Formalism. H istory-D octrine. La Haya: Mounton

\& Co., 1955 (El formalismo ruso. Barcelona: Seix Barral, 1974). Jakobson, Roman y Petr Bogatyrev. "El folklore como forma específica de creación". E nsayos de poética. Madrid: Fondo de Cultura Económica, 1977 ["Die Folklore als eine besondere Form des Schaffens". D onum N atalicium Schrijen. Nimega-Utrecht, 1929]. Jameson, Fredric. L a cároel del lenguaje. Perspectiva crítica del estructuralismo y del formalismo ruso. Barcelona: Ariel, 1979.

Jefferson, Ann. "Russian Formalism", en: Ann Jefferson and D avid Robey (Eds.), M odern L iterary Theory. A Comparative Introduction . Eds. Ann Jefferson y D avid Robey. Totowa, New Jersey, Barnes \& Noble Books, 1982.

Lázaro Carreter, Fernando. "Prólogo a la versión castellana", en

Boris Tomachevsky, Teoría de la literatura. Madrid: Akal, 1982. Shklovsky, Víctor. "El arte como artificio" (Todorov 55-70). Todorov, Tzvetan. Théorie de la Littérature. Tex tes des Formalistes ruses réunis, presentés et traduits. Pról. Roman Jakobson. París: Seuil, 1965 (Teoría de la literatura de los formalistas rusos. 2a. ed. Trad. Ana María Nethol. Buenos Aires: Siglo XXI, 1976). 
Trotsky, León. "La escuela formalista de poesía y el marxismo", Literatura y revolución. París: Ediciones de Ruedo Ibérico, 1968. 